\title{
Study of VLBW babies with reference to maternal risk factors at secondary level referral center
}

\author{
Ravichandra B. V. ${ }^{1}$, Santhi K. ${ }^{2}$ \\ ${ }^{1}$ Dr. Bonu Venkata Ravichandra, HOD Pediatrics, ${ }^{2}$ Dr. Santhi Kothapalli, Pediatrician, SNCU, District Hospital, \\ Vizianagaram, Andhra Pradesh, India.
}

Corresponding Author: Dr. Santhi Kothapalli, Pediatrician, SNCU, MCH Block, District Hospital, Vizianagaram, Andhra Pradesh, India. Email: sanbenj@gmail.com

\begin{abstract}
Background: To evaluate the maternal risk factors for VLBW babies delivered in the district hospital, Vizianagaram, mother and child health block, and to study preventive measures to reduce the birth of VLBW babies. Material \& Methods: The VLBW babies were studied during the period from Jan to Dec 2018 with the Obstetric Department to assess the possible complications of the mother with which these babies are delivered. Results: Total number of deliveries observed during the period from Jan to Dec 2018 are 8134, out of which 657 babies are born with LBW $(<2.5$ $\mathrm{Kgs}$ ) with the incidence of $8.85 \%$ and the incidence of VLBW babies is $0.65 \%$ among the 657 LBW babies 53 babies happens to be VLBW babies i.e. 7.36\% of LBW babies are VLBW babies. Out of 53 babies 7 babies expired while undergone treatment at SNCU due to sepsis, RDS, PVH. Maternal complications observed for VLBW babies are Anemia $(50 \%)$ infection $(10 \%)$ uterine anomalies (5\%) twins $(15 \%)$ post cesarean pregnancy with scar tenderness $(2 \%)$ antepartum hemorrhage (1\%) abnormal presentations (2\%) PROM (5\%) PIH (10\%). Conclusion: Lower socio-economic status and anemia were thought to be the significant factors influencing the birth of VLBW. In the present study infections, uterine anomalies, multi fetal gestations, abnormal presentations, PIH should be considered and their timely management with medicines and interventions like cervical encirclage by improve their neonatal outcome and can reduce the neonatal mortality and morbidity and thus minimize the burden of SNCU and NICU admissions.
\end{abstract}

Key words: VLBW, NMR predominantly

\section{Introduction}

Weight of the baby after delivery determines the survival chances of the infant, VLBW contributes NMR predominantly. In developed countries like US neonatal mortality is 4/1000/year (2011) as compared to India 28/1000/year and A. P 24/1000/year (2013), the major causes of NMR are LBW/Preterm and congenital anomalies in developed countries where as in India LBW/ Preterm labor, birth asphyxia and sepsis are continued to be the major contributory factors for NMR [1]. $2 / 3^{\text {rd }}$ of the IMR are related to NMR. Medical, socioeconomic and cultural factors influence in India for the high rate of NMR giving rise to 0.75 million deaths/year [2].

VLBW babies contribute to the bulk section of NMR and VLBW infants account for $50 \%$ of neonatal deaths.

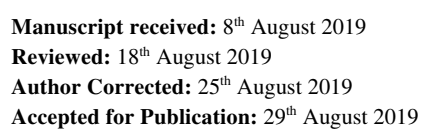

Among the various factors of identified causes of preterm birth in child, include multifetal gestation, placental abruption and uterine anomalies, maternal medical disorders, including GDM, PIH, infections, PROM, Trauma, abnormal presentations like breech [3-6]. The common causes of mortality in VLBW babies are RDS, HMD, BPD, Anemia, NEC, IVH, PVH, Seizures, Septicemia, metabolic abnormalities like hypoglycemia hypocalcaemia, hyperbilirubinemia and polycythemia. Identification of the causative factors during antenatal period can prevent the birth of VLBW infant.

Regular antenatal checkups to identify uterine anomalies and prompt cervical encirclage procedures, treatment of the asymptomatic bacteruria, early identification of PIH and treatment of gestational diabetes by glucose challenge test and with proper treatment of infections and anemia with proper 


\section{Original Research Article}

medication, identification of twins, arresting preterm labor with tocolytic drugs and progesterone, avoidance of trauma and coitus, journeys can minimize the VLBW babies birth. Close monitoring of placenta previa with rest, avoidance of constipation and avoidance of coitus can reduce the preterm deliveries. Advising adequate spacing of post-operative cases of cesarean section, nutritional education can minimize early scar tenderness and pre-disposition to hysterotomy in view of scar tenderness or scar dehiscence.

VLBW babies contribute majority of the NMR, so high index of suspicion with obstetric care and timely intervention can reduce the birth of VLBW babies. The VLBW babies can be burden to the society, financial burden to the family, cause overload to SNCU and NICU.

As per the sustainable development goals [1] the NMR has to be reduced from $28^{\text {th }}$ to $12 / 1000$ by 2030 and similarly under five mortality rates from 50 to $25 / 1000$, all preventive measures should be taken to minimize the preterm birth. The ANC and judicious obstetric management play crucial role to get the desired objective. Social and administrative reforms like JSY,
JSSK, PMSMY, incentives, nutritional supplementation of iron and calcium, health education, regular BP checkup, $\mathrm{Hb} \%$, blood glucose checkups and ultra sound scan examination contribute much more to improve the birth weight of the baby and thereby we can reduce the NMR and IMR.

\section{Materials and methods:}

Study of VLBW babies with reference to maternal factors is conducted at district hospital, mother and child health block, Vizianagaram, Andhra Pradesh, SNCU of Pediatrician Department. The data of VLBW babies i.e. 1 to $1.5 \mathrm{kgs}$ was collected from SNCU record. Data of respective mothers regarding maternal risk factors was collected from operation theatre register and parturition register, during the period from Jan 18 to Dec 18.

Inclusion criteria: Babies born in the hospital weighing between 1 to $1.5 \mathrm{kgs}$.

Exclusion criteria:Congenital anomalies, chromosomal abnormalities, syndromic babies. Ethical committee approval was taken.

\section{Results}

The number of deliveries conducted in the MCH block District Hospital is 8134 for 1 year from Jan 18 to Dec 18. 657 babies are born with weighing $2.5 \mathrm{kgs}$ or less. With the incidence of $8.85 \%$ and 53 babies are found to be VLBW babies with the incidence of $0.65 \%$, the LBW incidence is far high in India, in developed countries like US, it is $113 / 1,00,000$ corresponding is $8,850 / 1,00,0007$ babies were expired and 14 babies were referred to the higher centers due to various reasons. Among 53 VLBW babies 23 were found to have preterm deliveries (Table 1).

Table-1: Aetiological factors for VLBW babies.

\begin{tabular}{|l|c|c|}
\hline \multicolumn{1}{|c|}{ Factors } & $\begin{array}{c}\text { Present study at DH, VZM, } \\
\text { AP 2018 }\end{array}$ & Average Indian statistics \\
\hline Preterm birth related complications & $42 \%$ & $44 \%$ \\
\hline Sepsis, meningitis & $15 \%$ & $16 \%$ \\
\hline Congenital anomalies & $10 \%$ & $8 \%$ \\
\hline Term SGA & $2 \%$ & $4 \%$ \\
\hline Pneumonia & $5 \%$ & $1 \%$ \\
\hline Diarrohea & $1 \%$ & $19 \%$ \\
\hline Intra-partum related birth complications & $10 \%$ & $8 \%$ \\
\hline Others & $5 \%$ & \\
\hline
\end{tabular}

Antenatal complications observed are severe anemia $(<7 \mathrm{~g} \%) 50 \%$, infections $10 \%$, uterine anomalies $10 \%$, twins $15 \%$, scar tenderness $2 \%$, abruption placenta previa $3 \%$, PIH $10 \%$ as institution is a public sector in Govt. hospital almost all antenatal mothers are low socio economic status, poor literacy rate, with poor housing and overcrowding comes from rural areas. Their nutritional status is also low standard (Table 2). 
Original Research Article

Table-2: Comparative study of maternal complications of VLBW babies

\begin{tabular}{|l|c|c|c|}
\hline Complications & $\begin{array}{c}\text { Study by Shabana M Shaik } \\
\text { (Sangli, Maharastra) 2017 }\end{array}$ & $\begin{array}{c}\text { Mani Madhavan } \\
\text { (MMC, Tamilnadu) 2017 }\end{array}$ & $\begin{array}{c}\text { Present Study } \\
\mathbf{2 0 1 8}\end{array}$ \\
\hline PROM & $38 \%$ & $32 \%$ & $5 \%$ \\
\hline Anemia & $35 \%$ & $26 \%$ & $50 \%$ \\
\hline PIH & $18 \%$ & $42 \%$ & $10 \%$ \\
\hline Multiple pregnancy & $7 \%$ & - & $15 \%$ \\
\hline Mal presentations & $2 \%$ & - & $2 \%$ \\
\hline
\end{tabular}

The prognosis for VLBW is poor in view of prematurity, hypoglycemia, respiratory distress syndrome and septicemia. $80 \%$ of the babies died due to RDS or septicemia. The above statistical incidence shows majority of maternal complications are leading to preterm labor are PROM and deliver of very low birth weight babies (Table 3).

Table-3: Complications of VLBW babies observed in SNCU.

\begin{tabular}{|c|c|c|}
\hline Complications & No. of VLBW babies observed & Outcome at SNCU \\
\hline Hypothermia & $2(3.8 \%)$ & Discharged \\
\hline Hypoglycemia & $8(15 \%)$ & Discharged \\
\hline Seizures & $2(3.8 \%)$ & Referred \\
\hline PVH & $1(1.9 \%)$ & Expired \\
\hline Respiratory distress & $32(61.5 \%)$ & 4 Experred, 3 Expired \\
\hline Septicemia & $7(13.46 \%)$ & Expired \\
\hline
\end{tabular}

These incidence of VLBW babies presently thought to be due to infections, uterine anomalies, multifetal gestations, post cesarean pregnancy with scar tenderness and anti-partum hemorrhage, in contrary to the developed countries these incidences are due to mainly congenital anomalies, inborn errors of metabolism and rarely PROM. The survival rate is slightly increased due to establishment of new-born care corners and SNCU, follow-ups, usage of tocolytic drugs to arrest preterm delivery. Antenatal corticosteroids administration, usage of antibiotics for PROM cases. Birth weight of the neonate plays significant role in morbidity and mortality. High risk pregnancy identification and judicial management and timely obstetric intervention are the factors for successful outcome. VLBW babies contributes major percentage of NMR, IMR, SNCU and NICU overload.

\section{Discussion}

The outcome of a Neonate is predicted by its birth weight. The prognosis of a VLBW baby is considered poor unless managed by team in higher center i.e, NICU $[7,8]$. Obstetrics management is of great importance in reducing the births of VLBW babies. The birth of such babies is burden financially, socially, emotionally to the family members and to health care providers. Every attempt should be made to prevent the birth of VLBW babies by efficient obstetrics management of high-risk pregnancies.

Maternal conditions like PIH, GDM, Cardiac disorders, Jaundice, anemia, malnutrition, and congenital anomalies should be identified at an early stage and treatment be initiated [3]. Tocolytic drugs like
Nifedipine, Isoxsuprine, Oxytocin receptor antagonist, magnesium sulphate, ritodrine should be considered and used judiciously [4]. Prophylactic steroids should be administered to all cases of preterm labour and enhance pulmonary surfactants production. Serial measurement of growth and doppler velocemetry for utero placental insufficiency have to be done for early detection and proper management of IUGR [9-12].

In the present study, preterm labour and obstetrics related complications have the major share in the development of VLBW babies. Focus should be made on the above parameters. Genital tract infections, Urinary tract infections should be managed with appropriate antibiotic therapy. Multifetal gestation 


\section{Original Research Article}

should be given top priority and the antenatal checkups should be increased in view of possibility of PROM, Preterm labour [5]. Thus, obstetrics management plays key role, as the study is mainly concerned with maternal risk factors $[13,14]$.

Regarding the neonatal complications found in the present study were RDS, Sepsis and metabolic conditions like Hypoglycaemia, polycythemia, neonatal jaundice. In India with the target of achieving NMR $12 / 1000$ live births per year, the above factors should be considered in a systematic approach from primary level of health care to tertiary care centers $[15,16]$.

Preventive measures and recommendations: In majority of the situations, the birth of VLBW babies is preventable, early identification of maternal complications and management of the conditions are key role for the better outcome. As the NMR and IMR are very high in our country, every parameter should be considered with top priority in regular maternal checkups. Survival rate of VLBW babies are significantly low, however much care is taken by SNCU, NICU personal, it is better to aim at preventive measures by way of obstetric management.

1. Screening of high-risk pregnancy and follow-up visits should be increased.

2. Educations of Ashas, ANMs and all paramedical staff to identify high risk pregnancy.

3. Nutritional supplementation with iron, folic acid, calcium with high protein diet.

4. Screening of BP, GCT, Blood Group, control of infections should be given priority.

5. Early identification of cervical incompetence and other congenital anomalies and plan for cervical encirclage in selected cases.

6. Avoidance of trauma, journeys.

7. Multifetal gestations should be given top priority and there is every chance of APH, PROM. Now a days the incidence of twins is increasing due to ovarian stimulation protocols.

8. Tocolytic drugs like magnesium sulfate, ritodrine, isoxsuprine, progesterone should be used when indicated.

9. Antenatal Betamethasone $12 \mathrm{mg}$ IM $12^{\text {th }}$ hourly to enhance pulmonary surfactant production should be given all cases of preterm labor.

10. Lastly spacing should be advised and there should be adequate interval of subsequent pregnancies.

\section{Conclusion}

VLBW babies have high morbidity and mortality and contribute a major section of NMR Judicious obstetric intervention is of utmost importance in reducing the incidence of birth of VLBW babies. Health care service providers aim at better obstetric services as preventive measure.

\section{What this study adds to the existing knowledge?}

The present study reveals there has been an increased incidence of multi fetal gestation, cervical incompetence, PIH and post caesarian pregnancies with scar tenderness and abruption. Anemia, infections, congenital anomalies are now secondary factors, hence obstetric management is the only preventive care in decreasing the incidence of birth of VLBW babies.

\section{Authors contribution}

- Dr.BV Ravichandra: Planned and coordinated the study and drafted the manuscript.

- Dr. Santhi Kothapalli: Planned, collected and compiled the data, revised the manuscript

Funding: Nil, Conflict of interest: None initiated, Permission from IRB: Yes

\section{References}

1. United Nations Children's Fund and WHO: Low Birth Weight country, regional and global estimates. New York; 2004. Available at http://www.unicef.org/ publications/index_24840.html. Last accessed on 24 May 2013.

2. UNDP: Infants with low birth weight.Available at http://hdrstats.undp.org/indicators/67.html. Accessed on 17 December 2006.

3. Stoll BJ, Ira Adams Chapman. The high risk infant. In:Kliegman RM, Behrman RE, Jenson HB, Stanton BF, editors.NelsonTextbook of Pediatrics. Vol $1.18^{\text {th }} \mathrm{ed}$. New Delhi: Elsevier;2008. p.698-710.

4. Krishnan Lalitha, Chakladar BK. Maternal risk factors and low birth weight. J Obstet Gynecol India 1989; 39:52-57.

5. Rajaeefard A, Mohammadi M, Choobineh A. Preterm delivery risk factor: a prevention strategy in Shiraz, Islamic Republic of Iran. East Mediterr Health J. 2007; 13 (3):551-559. 
Original Research Article

6. Roy KK, Baruah J, Kumar S, Malhotra N, Deorari AK, Sharma JB. Maternal Antenatal Profile and Immediate Neonatal Outcome in VLBW and ELBW Babies. Indian J Pediatr. 2006;73(8):669-673.

7. Singh M, editor. Nomenclature and definitions. In: Care of the newborn. $6^{\text {th }}$ ed.New Delhi: Sagar Publications; 2004.p. 1-11.

8. Singh M, editor. Disorders of Weight and Gestation. In: Care of the newborn. $6^{\text {th }}$ ed. New Delhi: Sagar Publications; 2004.p. 219-38.

9. Long PA, Abell DA. Fetal growth retardation and pre-eclampsia. Brit J Obstet Gynecol.1980;87(1):13-18. doi:https://doi.org/10.1111/j.1471-0528.1980.tb04419.x

10. Bhaumik S, Ghosh S, Haldar KK, Mitra PK, Manna B. Risk of early on set neonatal septicemia in-babies born to-mothers with pre-eclampsia. Indian Pediatr. 2000: 37:775-9.

11. Nadkarni J, Bahl J, Parekh P. Perinatal Outcome in Pregnancy Associated Hypertension. Indian Pediatr. 2001; 38:174-178.
12. Sehgal A, Telang S, Passah SM, Jyothi MC. Matenial and neonatal profile and immediate outcome in ELBW babies. Pediatr. 2003;40:991-995.

13. Goldenberg RL, Culhane JF, Iams JD, Romero R. Epidemiology and causes of preterm birth. The Lancet. 2008; 371(9606):7 5-84. doi: 10.1016/S0140-6736(08) 60074-4.

14. Ballard JL, Khoury JC, Wedig K, Wang L, EilersWalsman BL, Lipp R. New Ballard Score, expanded to include extremely premature infants. J Pediatr. 1991; 119 (3): 417-423.doi: https://doi.org/10.1016/S00223476 (05) 82056-6

15. Roth J, Hendrickson J, Schilling M, Stowell DW: The risk of teen mothers having low birth weight babies: implications of recent medical research for school health personnel. J Sch Health. 1998: 68(7): 271-275.

16. Amin N, Abel R, Sampathkumar V. Maternal Risk factors associated with low birth weight. Indian J Pediatr. 1993;60(2):269-274.

\section{How to cite this article?}

Ravichandra B. V, Santhi K. Study of VLBW babies with reference to maternal risk factors at secondary level referral center. Int J Pediatr Res. 2019;6(08):424-428.doi:10.17511/ijpr. 2019.i08.06 